\title{
Dermatoglifika dłoni mieszkańców wyspy Palue (Indonezja): Thenar i Hypothenar
}

\author{
Richard Kiprono A. Mitei
}

PAPILIARY PATTERNS OF PALMS OF TIII: INIIABITANTS OI: PAI.UI: ISI AND (INI)ONI:SIA): 'TIII:NAR AND HYPOTIENAR. Frequencics of papillary patterns were compared with data for the Polish population and significant discrepancies were found.

Palue jest jedną z Malych Wysp Sundajskich należących do Indonezji. Ludność tej wyspy została zbadana i opisana pod względem antropologicznym przez GI.INKE [1971]. Cechy dermatoglificzne palców dłoni tej ludności przedstawili, w odrębnej publikacji, GLINKA, JASICKI, WIŚNIEWSKA [1983]. Informacje dermatoglificzne warto uzupelnić danymi o listewkach skórnych dloni.

$\mathrm{Na}$ podstawie materialu zebranego przez Józefa Glinkę w latach 1966-1977, opisano wzory dermatoglificzne na tenarze i hypotenarze dfoni 1777 doroslych mieszkańców wyspy Palue (733 kobiety i 1044 mężczyzn). Definicje wzorów i sposób opisu oparto na propozycjach CUMMINSA i MIDLO [1943], uzupelnionych przez LASIŃSKIEGO [1952].

Uwzględniono następujące wzory:

Zonlogy Department, Kenyatta University P.P. Box 43-844, Nairobi, Kenya
Na hypotenarze wyróżniano pola be' wzorów - $O$, wzory szczątkowe - $V$, luki - $A$, luki napięte (namiotowe) - $T$, pętle - $I$, i wiry - $W$. Wzory oznaczano ponadto pod względem kierunku - nadgarstkowego (c), dystalnego $(d)$, fokciowego $(u)$ i promicniowego $(r)$. W przypadku występowanial dwu wzorów, jako pierwszy wpisywano bardziej dystalny, na drugim micjscu, oddzielony skośną kreską, wzór proksymal ny.

Na tenarze wyróżniano: brak wzoru - (), wzory szczątkowe i nietypowe - $V$, luki - $A$, pętle - $L$ i wiry $W$ oraz kombinacje wzorów $A / L, L / L$ i $W / L$. W jednym przypadku wystąpila kombinacja $L / L / L$.

Opis dermatoglifiki uzupeiniono charakterystyką polożenia trójramiennika nadgarstkowego $(t)$, oraz trójramicnnikíw dloniowych $\left(t^{\prime}, t^{\prime \prime}, t^{u}\right)$. Zwrócono uwagę nat asymetrię wymienionych wyzej cech oril\% dymorfizm plciowy.

W tabeli 1 zestawiono danc dotycalace wzorów na hypotenarze. Zuccydowanic 


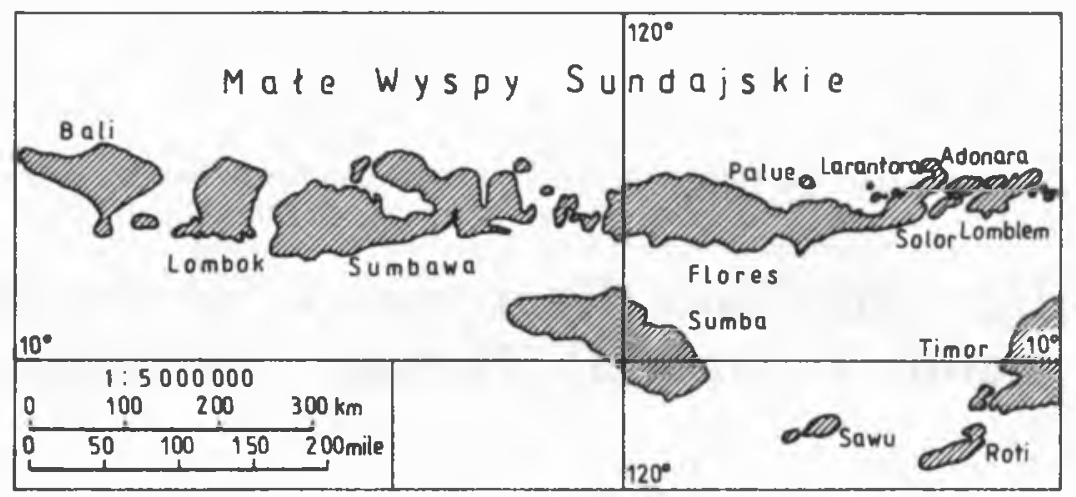

Rys. 1. Make Wyspy Sundajskie

Tabela 1. Wzory w polu bypothenar u mieszlrańców Palue

\begin{tabular}{|c|c|c|c|c|c|c|c|c|c|c|c|c|}
\hline \multirow[t]{3}{*}{ Wzór } & \multicolumn{6}{|c|}{ Mężczyźni } & \multicolumn{6}{|c|}{ Kobiety } \\
\hline & \multicolumn{3}{|c|}{ prawa } & \multicolumn{3}{|c|}{1 ewa } & \multicolumn{3}{|c|}{ prawa } & \multicolumn{3}{|c|}{ lewa } \\
\hline & $n$ & $\%$ & $\%$ & $n$ & $\%$ & $\%$ & $n$ & $\%$ & $\%$ & $n$ & $\%$ & $\%$ \\
\hline$O$ & 282 & 27,0 & & 334 & 32,0 & & 169 & 23,1 & & 160 & 21,8 & \\
\hline$V$ & 536 & 51,3 & & 495 & 47,4 & & 367 & 50,1 & & 351 & 47,0 & \\
\hline$A^{C}$ & 64 & 6,1 & 86,2 & 73 & 7,0 & 87,8 & 66 & 9,0 & 83,6 & 77 & 10,5 & 81,0 \\
\hline$A^{u}$ & 16 & 1,5 & & 13 & 1,3 & & 7 & 1,0 & & 6 & 0,8 & \\
\hline$A^{r}$ & 2 & 0,2 & & 1 & 0,1 & & 3 & 0,4 & & . & . & \\
\hline$T^{c}$ & 18 & 1,7 & & 17 & 1,6 & & 12 & 1,6 & & 25 & 3,4 & \\
\hline$T^{M}$ & 3 & 0,3 & & 2 & 0,2 & & - & . & & - & - & \\
\hline$L^{r}$ & 64 & 6,1 & 12,6 & 51 & 4,9 & 11,8 & 56 & 7,7 & 15,5 & 53 & 7,2 & 17,6 \\
\hline$L^{d}$ & 13 & 1,3 & & 26 & 2,5 & & 13 & 1,8 & & 18 & 2,5 & \\
\hline$L^{u}$ & 27 & 2,6 & & 22 & 2,1 & & 32 & 4,4 & & 27 & 3,7 & \\
\hline$L^{c}$ & 7 & 0,7 & & 5 & 0,5 & & 1 & 0,1 & & 6 & 0,8 & \\
\hline $\boldsymbol{W}$ & 4 & 0,4 & 0,4 & 2 & 0,2 & 0,2 & - & - & - & 2 & 0,3 & 0,3 \\
\hline$L / T$ & 1 & 0,1 & & . & $\cdot$ & & 1 & 0,1 & & 3 & 0,4 & \\
\hline$L / L$ & 7 & 0,7 & 0,8 & 3 & 0,3 & 0,3 & 5 & 0,7 & 0,8 & 3 & 0,4 & 1,1 \\
\hline$W / L$ & - & • & - & - & - & & - & - & & 2 & 0,3 & \\
\hline & 1044 & & 100 & 1044 & & 100 & 732 & & 00 & 733 & & 100 \\
\hline
\end{tabular}


przeważają na nim, na obu rękach i u obu plci, pola pozbawione wzorów lub z wzorami szczątkowymi. Wymienione dwie kategorie, lącznie z lukami, które uznać można za najmniej skomplikowane wzory, stanowią ponad $80 \%$ wszystkich przypadków, przy czym u mężczyzn jest ich więcej (86$87 \%)$ niż u kobiet $(81-83 \%)$. Różnica dla wartości lewych rąk $(6,8 \%)$ jest istotna statystycznie $\left(u^{0}=3,94, p<0,01\right.$; OKTABA [1966]). Częstość występowania dobrze uksztaltowanych wzorów $(T, L$ i $W)$ jest niewielka i wynosi ok. $12 \%$ u mężczyzn i 15$17 \%$ u kobiet. $Z$ bardzo niską częstością, na ogól poniżej $1 \%$, występowaly kombinacje figur $(L / T, L / L \mathrm{i} W / L)$. Niewielkie różnice w częstościach poszczególnych kategorii ukladów listewek na prawych i lewych rękach zaznaczyly się jedynie u kobiet, choć i u nich nie można różnic tych uznać za istotne ( $n^{\circ}$ dla największej $z$ różnic wynosi 1,30 , co oznacza, że $p>0,05$ ).

W tabeli 2 zestawione zostaly wyniki analizy wzorów na tenarze. Podobnie jak na hypotenarze, tu również wyraźnie przeważają pola bez figur, o wzorach szczątkowych lub nieskomplikowanych $(O, V, A)$. Częstości takich pól wynoszą u mężczyzn $77-78 \%$, u kobiet $81-86 \%$. Występuje więc tendencja przeciwna do zaobserwowanej na hypotenarze: więcej sprecyzowanych wzorów ( $L, W$ i ich kombinacje) spotyka się na dloniach mężczyzn. Dla prawych rąk różnica wynosząca $9,5 \%$ jest wysoce istotna $\left(n^{0}=5,05, p<0,001\right)$.

Różnica między prawą i lewą ręką zaznacza się wyraźniej jedynie u kobiet - wzory występują częściej na tenarze lewej ręki $\left(n^{0}=2,86, p<0,05\right)$.

Tabela 3 przedstawia częstości trójramienników nadgarstkowych oraz dloniowych $\left(t, t^{\prime}, t^{\prime \prime} i t^{\mu}\right)$. U obu plci stosunkowo często stwierdza się brak trójramiennika $t$ (17 - 21\%), nieco częściej u mężczyzn, choć różnica nie osiąga akceptowalnego poziomu istotności $\left(n^{0}=1,90 ; 0,06>\right.$ $>p>0,05$ ). Pomiędzy ręką prawą i lewą różnice są niewielkie i nieistotne.

Tabela 2. Wzory w polu thenar u mieszkanców Palue

\begin{tabular}{|c|c|c|c|c|c|c|c|c|c|c|c|c|}
\hline \multirow[t]{3}{*}{ Wzór } & \multicolumn{5}{|c|}{ Męźczyźni } & & \multicolumn{6}{|c|}{ Kobiety } \\
\hline & \multicolumn{2}{|c|}{ prawa } & & \multicolumn{2}{|c|}{ kwa } & & \multicolumn{2}{|c|}{ prawa } & & \multicolumn{2}{|c|}{ kewa } & \multirow[b]{2}{*}{$\%$} \\
\hline & $n$ & $\%$ & $\%$ & $n$ & $\%$ & $\%$ & $n$ & $\%$ & $\%$ & $n$ & $\%$ & \\
\hline$o$ & 321 & 30,7 & & 279 & 26,7 & & 275 & 37,5 & & 236 & 32,3 & \\
\hline$v$ & 483 & 46,3 & 77,1 & 529 & 50,7 & 78,0 & 360 & 49,1 & 86,6 & 357 & 48,8 & 81,1 \\
\hline$A$ & 1 & 0,1 & & 6 & 0,6 & & - & - & & - & • & \\
\hline$L^{r}$ & 118 & 11,3 & & 126 & 12,1 & & 38 & 5,2 & & 53 & 7,3 & \\
\hline$L^{L}$ & 28 & 2,7 & 15,2 & 2 & 0,2 & 15,3 & 12 & 1,6 & 7,9 & 11 & 1,5 & 12,0 \\
\hline$L^{c}$ & 13 & 1,2 & & 23 & 2,2 & & 8 & 1,1 & & 19 & 2,6 & \\
\hline$L^{d}$ & - & - & & 9 & 0,9 & & - & $\cdot$ & & 5 & 0,7 & \\
\hline$w$ & 27 & 2,6 & & 13 & 1,3 & & 18 & 2,5 & & 12 & 1,6 & \\
\hline$L / L$ & 53 & 5,1 & 7,7 & 45 & 4,3 & 6,8 & 22 & 3,0 & 5,5 & 38 & 5,2 & 6,8 \\
\hline$w / L$ & - & - & & 11 & 1,1 & & - & - & & - & - & \\
\hline \multirow[t]{2}{*}{$L / L / L$} & - & - & & 1 & 0,1 & & - & - & & - & $\cdot$ & \\
\hline & 1044 & & 100 & 1044 & & 100 & 731 & & 100 & 733 & & 100 \\
\hline
\end{tabular}


Tủbela 3. Czçstości trójramiennikớw dloniowych $t, f^{\prime}, t^{m} i t^{\mu}$ u mieszkanców Palue

\begin{tabular}{|c|c|c|c|c|c|c|c|c|c|c|c|c|}
\hline \multirow[t]{3}{*}{ Pokvizenic } & \multicolumn{6}{|c|}{ 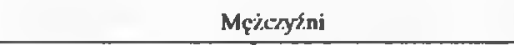 } & \multicolumn{6}{|c|}{ Kobicty } \\
\hline & \multicolumn{3}{|c|}{ prawa } & \multicolumn{3}{|c|}{ kewa } & \multicolumn{3}{|c|}{ prawa } & \multicolumn{3}{|c|}{ kwa } \\
\hline & $n$ & $\%$ & $\%$ & $n$ & $\%$ & $\%$ & $n$ & $\%$ & $\%$ & $n$ & $\%$ & $\%$ \\
\hline brak & 165 & 15,8 & & 173 & 16,6 & & 86 & 11,7 & & 79 & 10,8 & \\
\hline$r$ & 46 & 4.4 & 20,6 & 50 & 4,8 & 21,6 & 33 & 4,5 & 17,0 & 55 & 7,5 & 19,1 \\
\hline M & 4 & 0.4 & & 2 & 0,2 & & 6 & 0,8 & & 6 & 0,8 & \\
\hline 1 & 684 & 65.5 & & 676 & 64,8 & & 444 & 60,6 & & 464 & 63,3 & \\
\hline$r$ & 9 & 9.2 & 74,7 & 102 & 9,8 & 74,6 & 110 & 15,0 & 75,6 & 9 & 13,1 & 76,4 \\
\hline$"$ & 7 & 0.7 & & 12 & 1.2 & & 7 & 1,0 & & 4 & 0,6 & \\
\hline$n^{\prime}$ & 23 & 2.2 & & 13 & 1,2 & & 28 & 3,8 & & 20 & 2.7 & \\
\hline$" n$ & 13 & 1,2 & 4.7 & 14 & 1,3 & 3,9 & 17 & 2,3 & 7,3 & 9 & 1,2 & 45 \\
\hline$n^{d t}$ & 4 & 0.4 & & 1 & 0,1 & & 1 & 0,1 & & - & - & \\
\hline in" & 1 & 0,1 & & 1 & 0,1 & & 1 & 0,1 & & - & - & \\
\hline \multirow[t]{2}{*}{$\therefore$} & 1 & 0.1 & & - & - & & - & - & & - & - & \\
\hline & $10+4$ & & 100 & 1044 & & 100 & 733 & & 100 & 733 & & 100 \\
\hline
\end{tabular}

Podsumowując można stwierdzic, co nistępuje

1. Ludnośc Palue charakteryzuje się niewielką intensywnościa wzorów na hypotenarze. Częstość wzorów pẹtlicowych, wirowych $i$ ich kombinacji na rękach Polaków jest okolo 2 razy wyższa [BuCHWAl.d 1982, Rogucka 1973]. Różnica plciowa polega na częstszyn występowaniu dobrze uksztaltowanych wzorów u kobiet.

2. Na tenarze wyráznie uksztaltowane wzory $(L, W)$ wystẹpuja u mieszkańców Palue stosunkowo cz̧̧sto (częściej niż u Polaków), przy czym częśsiej u mężczyzn niż u kobict.

3. Różnice w częstościach występowania wzorów na prawej i lewej ręce sa slabo zaznaczone. Jedynic na tenarze kobiet różnica okazala się istotna (wzory częstsze na lewej dloni).

\section{Piśmiennictwo}

BUCHWAlD W., 1982. Uklad lislewick skdmych nas dioniach u Judnosci Polski poiłnocnej. Przegl. Antrop., 48. 25.

CUmmins H. C. MIDLO. 1943. Finger prinus, palms and soles, New York.

GLINKA J., 1971. Pochodzenic mieszkaric ow nyspy Palue (Make Hyspy Sundajskic) w' fwicule badan antropologicznych, Mal، i Prace Autrop., 81, 105.

GlinkA J., B. JASICKI, E. WIŚNIEWSKA, 1983, Dic Bewilkereng der Insel Paluc (Indone'sicn) im Lishe' der Fingerbeceren Atdrücke, Przegl. Antrop.. 49. 139.

LASIŃSKI W., 1952, vklad listewe'k skómy'ch na disniach Polaksw. Pracgl. Antrop.. 18. 159. 
OKTABA W., 1966, Elementy statystyki masematycznej i mesodyka doswiadezalnienwa, Wyd. 2, Warszawa.

ROGUCKA E., 1973, Variation and inherisance of dermatoglyphic features of the palm, Mat. i Prace Antrop., 86, 55.

Maszynopis nadesłano w maju 1986 r.

\section{S u m m a r y}

In supplement of the elaborations by GLINKA [1971], and GLINKA, JASICKI and WISNIEWSKA [1983] the author presented a description of palm dermatoglyphics of 1777 inhabitants of Palue island (Lesser Sunda islands). He found a comparatively low frequency of true patterns both on the Thenar and Hypothenar. Differences in the occurrence of patterns on the right and left hands were we akly manifested, on the other hand small differences between sexes have been found. 